\title{
Effects of shock-induced arousal on the elicitation and waveform elaboration of photically evoked afterdischarges
}

\author{
ERIN D. BIGLER \\ Division of Neurobiology, Barrow Neurological Institute of St. Joseph's Hospital and Medical Center \\ Phoenix, Arizona 85013 \\ and
}

DONOVAN E. FLEMING

Brigham Young University, Provo, Utah 84602

\begin{abstract}
The effects of an activating stimulus (unsignaled tailshock) on the elicitation and waveform elaboration of photically evoked afterdischarges $(\mathrm{PhADS})$ were examined. Tailshocks administered 1 sec prior to each photic stimulus presentation resulted initially in significant suppression of $\mathrm{PhAD}$ activity. With time PhADs could be elicited, but at attentuated levels. Hippocampal EEG rhythms simultaneously recorded during shock treatment initially exhibited a predominance of rhythmical slow-wave activity (RSA). With time, hippocampal EEG was characterized by a mixture of RSA and irregular large-amplitude slow waves. The results are discussed in terms of a proposed heuristic model relating PhAD activity to "arousal" level.
\end{abstract}

The rat visually evoked response (VER, see Figure 1), cortically recorded, is characterized by a primary positive-negative (P1-N1) wave complex followed by secondary components (P2-P3) and afterdischarge activity ( $\mathrm{P} 3$ on). The examination of photically evoked afterdischarge (PhAD) bursting in the rat has revealed a number of important neurobiological events. For example, systematic changes in PhAD activity correlate well with different behavioral processes (Klingberg, 1970; Klingberg \& Pickenhain, 1967; Pickenhain \& Klingberg, 1965; Pond \& Schwartzbaum, 1972; Schwartzbaum, Kreinick. \& Gustafson, 1971); the effects of $x$-ray irradiation can be quantified in terms of changes in PhAD bursting patterns (Klingberg, 1967); alterations in PhAD elicitation and waveform correlate well with neural maturation (Klingberg \& Schwartze, 1966) as well as with developmentally induced sensory changes (Heron \& Anchel, 1964; Rhodes \& Fleming, 1970); PhAD activity has been shown to be functionally dependent upon visual stimulation parameters that have long been known to affect visual

A major portion of this investigation was undertaken in the Physiological Psychology Laboratory, Brigham Young University and was supported by the Research Division, Brigham Young University. Provo, Utah. E. D. Bigler, during the writing of this manuscript, was supported by GRS Grant RR-05575. Additional support by Barrow Neurological Institute of St. Joseph's Hospital and Medical Center. Phoenix, Arizona and the assistance of Rozella Dean and Joy Harvey is gratefully acknowledged. Address reprint requests to Erin David Bigler, Division of Neurobiology, Barrow Neurological Institute of St. Joseph's Hospital and Medical Center. 350 West Thomas Road, Phoenix, Arizona 85013.

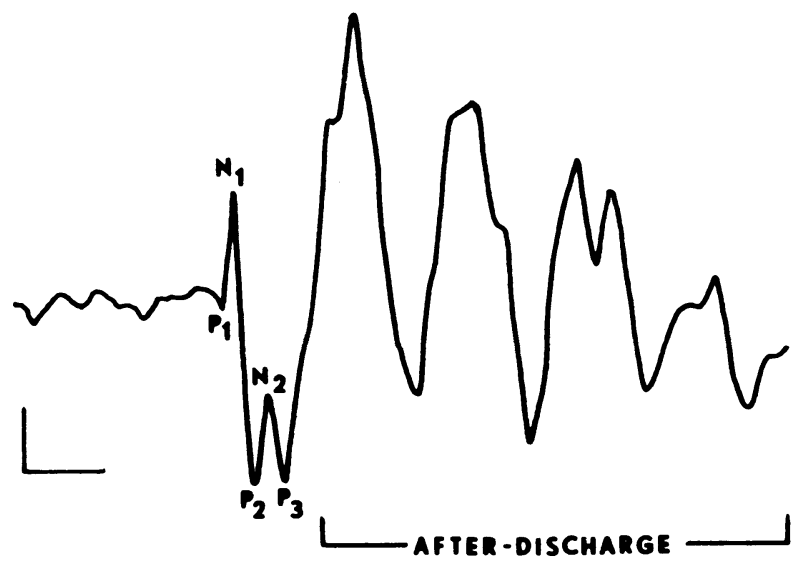

Figure 1. A typical averaged VER from rat occipital cortex recorded over 25 trials with five early waves labeled $P_{1} \cdot P_{3}$ followed by rhythmic afterdischarge activity. Stimulus onset was delayed 250 msec. Negativity is indicated by an upward deflection (Calibrations: 30 microV; $100 \mathrm{msec}$ ).

perception and functioning (Gelbrich, Klingberg, \& Rebentisch, 1972; Kohler \& Klingberg, 1969; Klingberg \& Pickenhain, 1966; Theil \& Klingberg, 1971; Yellin \& Jerison, 1973); cortical PhAD activity directly relates to dorsal lateral geniculate activity (Bigler, 1975; Kohler \& Klingberg, 1969; Sumitomo \& Klingberg, 1972a) as well as to other diencephalic, mesencephalic, and limbic system activity (Fleming \& Bigler, 1974; Kimura, 1962; Schwartzbaum. 1975; Sumitomo \& Klingberg, 1972b,c; Theil \& Klingber, 1971); the occurrence of PhAD activity has been utilized in the assessment of visual system morphology 
(Creel. Dustman, \& Beck, 1970, 1973; Kohler \& Klingberg, 1969, 1971; Sumitomo \& Klingberg, 1972a.b.c); pharmacological modulation of PhAD responding provides an excellent paradigm for the evaluation of central drug action (Bigler, 1975; Bigler \& Fleming, in press; Bigler, Fleming, \& Shearer, 1974: Fleming, Rhodes, Wilson, \& Shearer, 1972, 1973) as well as a neuropharmacological model for experimental epilepsy (Bigler, 1975; Shearer, Fleming, Bigler, \& Wilson, 1974).

The parameters affecting the elicitation of the primary and secondary components of the VER have received extensive documentation (see Beck, 1975), while those affecting PhAD elicitation have not been as extensively documented even though afterdischarge activity is a very common feature in VERs of many species including man (see Creel, Dustman, \& Beck, 1973). Current research has demonstrated that PhADs are readily suppressed or not elicited during conditions that apparently alter organismic arousal levels. Thus suppression or elimination of $\mathrm{PhAD}$ activity occurs during the acquistion phase of instrumental avoidance responding (Pickenhain \& Klingberg, 1965), behavioral reactivity (Schwartzbaum, Kreinick, \& Mello, 1972), brainstem electrical stimulation (Kimura, 1962), general ambulation (Fleming \& Bigler, 1974), genetically determined reactivity (Fleming, Wilson, \& Shearer, 1973), habituation (Bigler \& Fleming, 1974; Fleming et al., 1972; Rhodes \& Fleming, 1970), pharmacologically induced arousal (Bigler \& Fleming, in press; Bigler et al., 1974; Fleming et al., 1972), and sensory restriction (Rhodes \& Fleming, 1970). One unexplored parameter of arousal level on PhAD suppression has been the effect of delivering an activating stimulus to the animal immediately preceding the photic pulse. Using unsignaled tailshock as such a stimulus, the present investigation examined its effects upon the elicitation and waveform elaboration of PhAD activity. Dorsal hippocampal EEG was monitored as an ancillary measure because of the existing relationships between PhAD occurrence and certain hippocampal rhythms (see Bigler \& Fleming, in press; Fleming \& Bigler, 1974).

\section{METHOD}

\section{Subjects and Surgery}

Five Holtzman albino rats served as subjects. All subjects were at least 100 days old prior to surgery. Each animal was anesthetized with pentobarbital sodium $(40 \mathrm{mg} / \mathrm{kg})$ and surgically prepared with chronic indwelling silver-ball electrodes placed on the dura over the right and left visual cortices $(7.0 \mathrm{~mm}$ posterior to the bregman, $3.0 \mathrm{~mm}$ lateral to the midline). A stainless steel screw electrode was placed in the frontal sinus for grounding. A nichrome wire attached to the perimeter of the skull provided a reference attachment. In three subjects, a bipolar electrode consisting of two stainless steel Size 00 insect pins insulated with epoxylite except for the etched tips was stereotaxically positioned in the right dorsal hippocampus ( $3.0 \mathrm{~mm}$ posterior to bregma, $2.0 \mathrm{~mm}$ lateral to midline, $3.5 \mathrm{~mm}$ ventral from cortical surface). All electrodes were attached to female amphenol receptacles and imbedded and affixed to the skull surface with dental acrylic plastic and the wound closed. A minimum of 7 days recovery was allowed after which each subject was given at least 4 days acclimation training to the experimental environment. The location of hippocampal electrodes was histologically verified to be within the pyramidal cell layer.

\section{Apparatus}

A Gross PS22 photostimulator was positioned $42.5 \mathrm{~cm}$ behind and slightly above the midpoint of a flat white reflecting hemicylinder. The subject was placed in a restraining hammock which was positioned such that the subject's head region was encompassed $180 \mathrm{deg}$ by the reflecting hemicylinder. This insured equal presentation of the photic stimulus irrespective of momentary changes in subject's head position. The photostimulator was programmed to deliver 10 microsec pulses every $7 \mathrm{sec}$ to the reflecting surface. Photostimulator intensity was 4 on a scale of 1-16, with the illuminance of the reflecting surface being approximately $5 \mathrm{ftC}$. The entire apparatus was located within a shielded enclosure in a darkened room with background white noise. All procedures were carried out in unanesthetized animals with mydriatic pupils ( $1 \%$ atropine sulfate opthalmic solution). Brain responses were amplified with Grass 5P5 preamplifiers and Model 5 polygraph driver amplifiers (bandwidth, $.3 \cdot 60 \mathrm{~Hz}$ ), and ink-written records were obtained.

\section{Procedure}

Each subject was placed in the hammock and held under light restraint. A bipolar electrode connected to a Grass Model S9 stimulator was affixed to the tail which had been treated with electrode paste to insure electrical conductance. The subject was then given a 15-min period to dark adapt and acclimate to the restraining apparatus. Following this acclimation period, iterative photic stimulation was initiated for a total of 75 photic stimulus presentations. Commencing with the 26th photic presentation (the first 25 photic stimulus presentations constituted a preshock control period) a tailshock ( $1.5 \mathrm{~mA}$ for $100 \mathrm{msec})$ was delivered $1 \mathrm{sec}$ prior to each photic pulse for the next 25 flashes (Trials 26-50). Shock was discontinued following the 50th flash with iterative photic stimulation continuing for $\mathbf{2 5}$ more presentation trials (these last 25 trials constituted a postshock control). Thus, a total of 75 photic stimuli were presented in the following manner: preshock control (Trials 1-25); shock treatments administered 1 sec prior to each photic flash (Trials 26-50); postshock control (Trials 51-75). The entire procedure took approximately $30 \mathrm{~min}$ to complete.

\section{Data Analysis}

$\mathrm{PhAD}$ activity was analyzed in only the right visual cortex although both cortices were simultaneously monitored. Each block of 25 responses was broken down into blocks of five consecutive responses for data analysis. Three measures of PhAD activity were taken for each trial. The first was a measure (in millimeters) of the linear excursion of PhAD bursting. This was achieved by tracing the EEG inscription of the PhAD with a map-reading wheel. The second was to measure the duration (in milliseconds) of PhAD bursting. The third was to measure the number of spindle-like waves per PhAD burst. Each measurement initiated with the $\mathrm{N}_{3}$ wave and continued until PhAD activity could no longer be differentiated from background EEG. For all three measures of PhAD waveform activity means were calculated for each block of five responses. and analysis of variance techniques were used for statistical examination of the data.

\section{RESULTS AND DISCUSSION}

The results are summarized in Table 1 and Figure 2. The effect of introducing an activating stimulus (tailshock) prior to the presentation of a photic pulse was to significantly suppress all PhAD 
Table 1

Mean ( \pm Standard Error of the Mean) Treatment Effects on PhAD Parameters

\begin{tabular}{ccccc}
\hline $\begin{array}{c}\text { Trial } \\
\text { Block }\end{array}$ & $\begin{array}{c}\text { Linear Excursion } \\
\text { (in mm) }\end{array}$ & $\begin{array}{c}\text { Duration } \\
\text { (in msec) }\end{array}$ & $\begin{array}{c}\text { Spindle- } \\
\text { Like Waves }\end{array}$ \\
\hline Control & & & & \\
$1-5$ & $104.96 \pm 28.95$ & $387.96 \pm 65.66$ & $2.92 \pm .51$ \\
$6-10$ & $110.25 \pm 16.47$ & $477.29 \pm 50.00$ & $3.36 \pm .43$ \\
$11-15$ & $161.53 \pm 13.10$ & $703.93 \pm 81.86$ & $4.72 \pm .63$ \\
$16-20$ & $153.09 \pm 20.85$ & $578.61 \pm 99.99$ & $4.40 \pm .94$ \\
$21-25$ & $132.17 \pm 16.51$ & $529.28 \pm 49.33$ & $3.96 \pm .28$ \\
Shock & & & & \\
$26-30$ & $75.35 \pm 32.22$ & $290.64 \pm 114.66$ & $2.24 \pm .94$ \\
$31-35$ & $63.25 \pm 22.74$ & $245.31 \pm 78.99$ & $1.76 \pm .65$ \\
$36-40$ & $91.35 \pm 18.65$ & $377.30 \pm 59.66$ & $2.60 \pm .46$ \\
$41-45$ & $72.70 \pm 24.10$ & $274.64 \pm 75.99$ & $2.24 \pm .49$ \\
$46-50$ & $110.12 \pm 27.72$ & $449.29 \pm 122.32$ & $3.52 \pm .94$ \\
Control & & & & \\
$51-55$ & $173.00 \pm 32.67$ & $629.27 \pm 85.66$ & $4.88 \pm .74$ \\
$56-60$ & $128.65 \pm 19.88$ & $494.62 \pm 45.00$ & $3.48 \pm .48$ \\
$61-65$ & $134.69 \pm 26.93$ & $510.62 \pm 113.66$ & $3.52 \pm 1.40$ \\
$66-70$ & $135.58 \pm 13.45$ & $551.94 \pm 59.66$ & $4.00 \pm .32$ \\
$71-75$ & $143.64 \pm 13.45$ & $609.27 \pm 85.66$ & $4.28 \pm .67$ \\
\hline
\end{tabular}

parameters measured (PhAD linear excursion, $\mathrm{F}=2.71, \quad \mathrm{df}=14 / 56, \quad \mathrm{p}<.005 ; \quad$ PhAD burst duration, $\mathrm{F}=3.13$, $\mathrm{df}=14 / 56, \mathrm{p}<.001$ waves per PhAD burst, $F=2.24$, df $=14 / 56, p<.025$ ). Based on these significant findings, Newman-Keuls tests examining all pairs of means comparisons (Winer, 1962) revealed that the most suppressive effects on all PhAD parameters occurred during shock trials $26-30,31-35$, and $41-45$ as compared to control blocks $11-15,16-20,51-55$, and $71-75$.

PhAD parameters have been shown to be differentially affected during pharmacological arousal (Bigler \& Fleming, in press) or following habituation procedures (Bigler \& Fleming, 1974). However, following the induced arousal procedures of the present experiment, suppression of $\mathrm{PhAD}$ parameters could not be interdifferentiated; they were all equally suppressed.

Figure 3 depicts the initial effects of shock treatment on PhAD activity and hippocampal EEG rhythms. In terms of hippocampal EEG, the period prior to the first shock stimulus exhibited a relative predominance of large-amplitude irregular slow waves (LIA). However, with the initiation of the first shock stimulus, hippocampal EEG shifted to a relative predominance of rhythmical slow-wave activity (RSA or "theta") with PhAD bursting being noticeably absent. These findings complement and extend the previous work by Fleming and Bigler (1974) on the relationship between $\mathrm{PhAD}$ elicitation and spontaneous hippocampal RSA by demonstrating that a similar relationship exists during periods of induced or elicited hippocampal RSA and PhAD suppression.

In terms of shock modulation of PhAD waveform, inspection of Table 1 reveals that some degree of adaptation to the shock occurred. During shock treatments $46-50$, all $\mathrm{PhAD}$ parameters were above the initial control blocks $(1-5$ and most of $6-10$ preshock control samples). Also, the differences between PhAD parameters during $46-50$ shock treatments and 51 - 55 postshock control trials were not reliable even though PhAD parameter values reached a maximum during trials $51-55$. Thus PhAD waveform during the latter shock treatments was stabilizing, albeit at a somewhat suppressed level. Concomitant with this stabilization of PhAD waveform during the latter shock treatments, hippocampal EEG shifted from the early predominance of RSA back to a mixture of LIA and RSA.

Bigler and Fleming (1974) have argued that if arousal can be considered on a continuum, then an optimal arousal level may exist for PhAD elicitation and waveform maximization. Conversely, changes in arousal level above (e.g., those induced by pharmacological arousal, sensory restriction, etc.) or below (e.g., those following habituation) this optimal level would be associated with PhAD suppression. That PhAD activity occurs only within an optimal
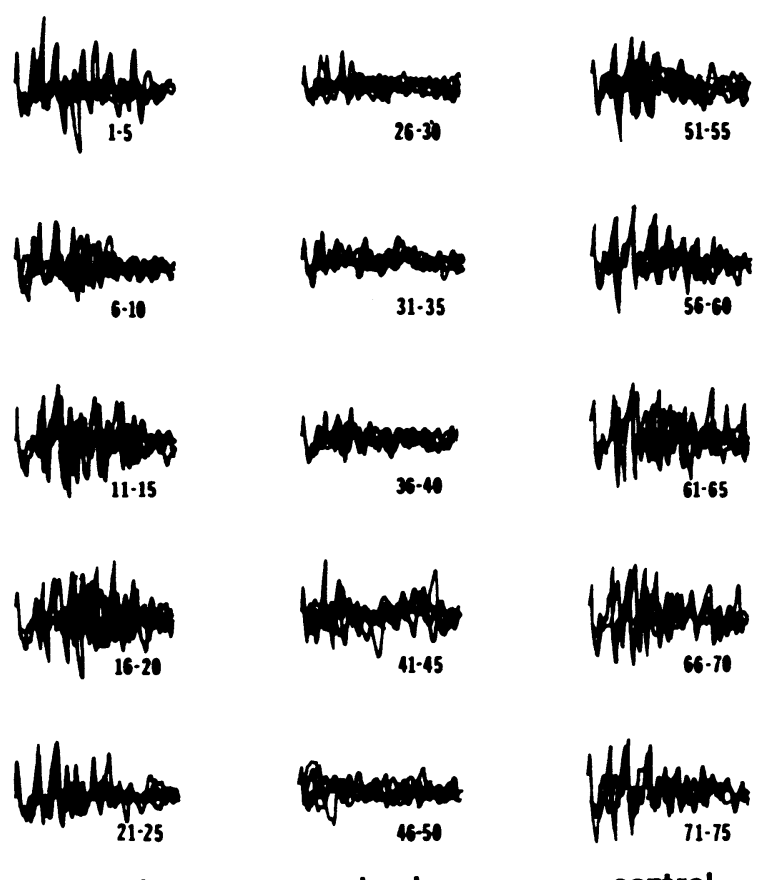

control

shock

control
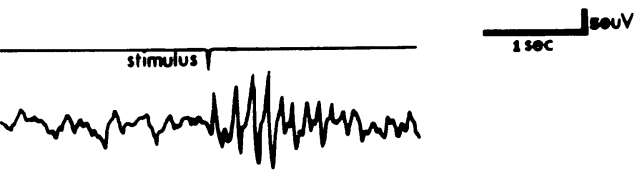

Figure 2. Effects of tailshock on $\mathrm{PhAD}$ activity in one subject. Each grouping is composed of five consecutive EEG inscriptions which are superimposed. The number range in the lower right-hand corner for each grouping designates which five consecutive responses were superimposed. The EEG tracing at the base of the illustration represents a typical "raw-data" evoked potential followed by PhAD bursting during control procedures. In all cases, negativity is an upward deflection. 

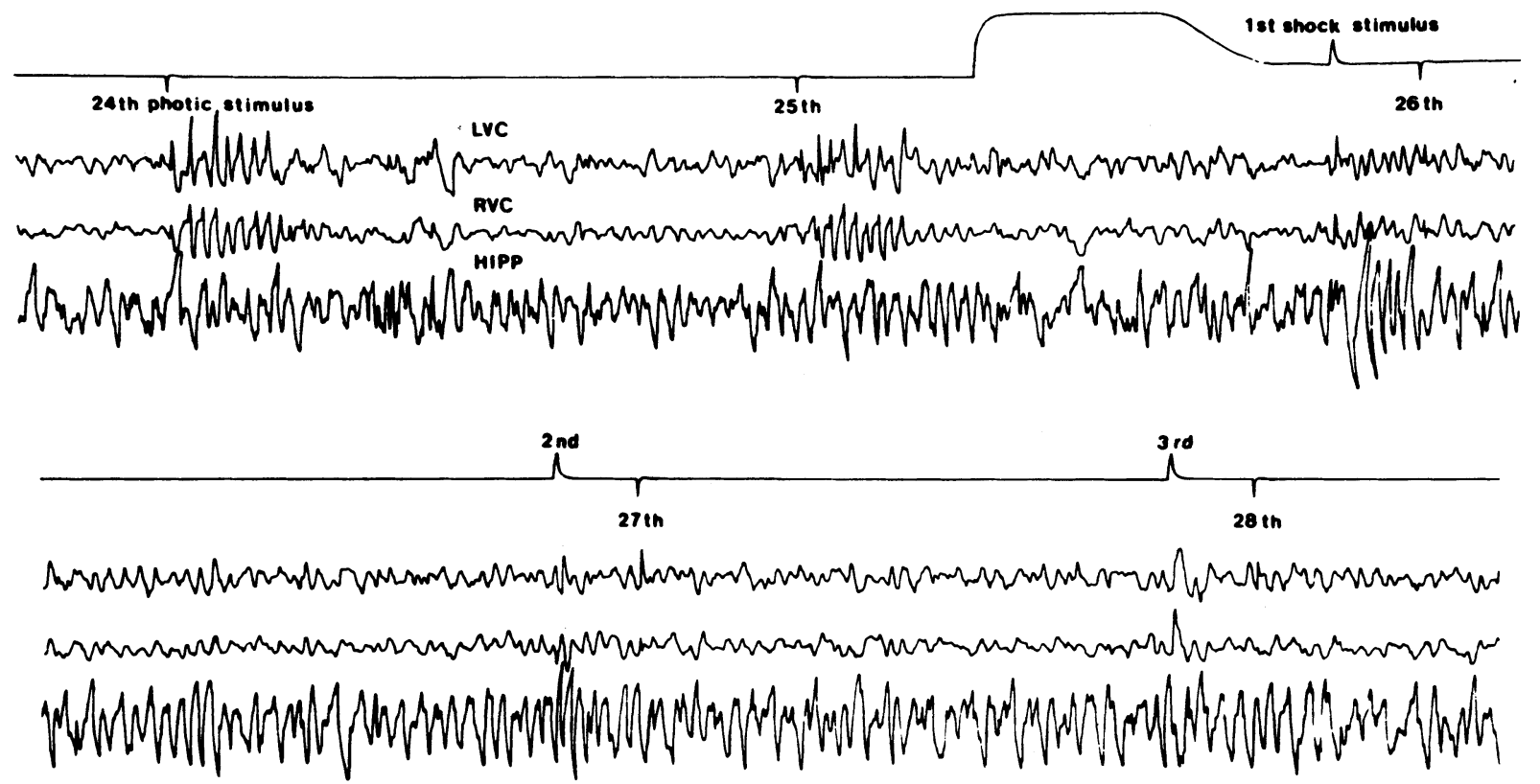

Figure 3. A continuous sequence of left visual cortical (LVC), right visual cortical (RVC), and dorsal hippocampal (HIPP) EEG during control photic stimulation (24th and 25th photic stimulus trials) and tailshocks administered 1 sec prior to each photic stimulus (26th-28th photic stimulus trials). Negativity is an upward deflection.

arousal interval appears to be a reasonable heuristic paradigm in explaining the present results. Thus, the initial effects of the shock were to heighten arousal to a level incompatible with PhAD elaboration. With time, arousal level gradually diminished from the heightened state to a point where PhADs were elicited, although at suppressed levels. If arousal level is playing the key role in $\mathrm{PhAD}$ elicitation, then it may be possible that a titration type of methodology could be applied. Accordingly, this could be quantified by systematically increasing and decreasing arousal level while concomitantly recording PhAD elicitation/ nonelicitation.

Although the objectives of this investigation were not directed towards testing the effects of classical conditioning on PhAD activity, the experimental design employed was similar to a form of classical conditioning (i.e., backward conditioning, Hilgard \& Bower, 1966, p. 54). Since the results of this investigation indicate that PhADs undergo systematic changes during behavioral arousal per se, it seems likely that PhADs will exhibit orderly relationships with conditioning processes. Presently, PhADs have only been investigated during the development of an instrumentally conditioned avoidance response (Pickenhain \& Klingberg, 1965) and during different behavioral sequences of fixed-ratio operant responding (Pond \& Schwartzbaum, 1972; Schwartzbaum et al., 1972). Since PhADs are intimately related to the VER secondary components (Creel, Dustman, \&
Beck, 1974; Fleming, Shearer, Creel, 1974; Schwartzbaum et al., 1971) and VER secondary components are systematically related to a variety of neural and behavioral processes (Begleiter \& Platz, 1969; John, Bartlett, Shimokochi, \& Kleinman, 1973; Rosenfeld \& Owen, 1972) the study of the effects of a variety of classical and operant-conditioning paradigms on $\mathrm{PhAD}$ parameters could yield more profitable results.

\section{REFERENCES}

BECK, E. C. Electrophysiology and behavior. In M. R. Rosenweig, \& L. W. Porter (Eds.), Annual review of psychology. Palo Alto: Annual Reviews, Inc., 1975.

Begleiter, H., \& Platz, A. Evoked potentials: Modifications by classical conditioning. Science, 1969, 166, 769-771.

Bigler, E. D. Lateral geniculate multiple-unit activity related to Metrazol potentiated after-discharges. Electroencephalography and Clinical Neurophysiology, 1975, in press.

Bigler, E. D., \& Fleming, D. E. Pharmacological suppressions of photically evoked after-discharges in rats: Incremental dose, hippocampal EEG and behavioral activity correlates. Psychopharmacologia, in press.

Bigler, E. D., \& Fleming, D. E. Habituation and the occurrence of photically evoked after discharges in the albino rat. Bulletin of the Psychonomic Society, 1974, 4, 275-277.

Bigler, E. D., Fleming, D. E., \& Shearer, D. E. Pharmacological modulation of photically evoked afterdischarge patterns in hooded Long-Evans rats. Bulletin of the Psychonomic Society, 1974, 4, 179-181.

Creel, D. J., Dustman, R. E., \& Beck, E. C. Visually evoked responses in the rat, guinea pig, cat, monkey, and man. Experimental Neurology, 1973, 40, 351-366. 
Creel, D. J., Dustman, R. E., \& Beck, E. C. Intensity of flash illumination and the visually evoked potential of rats, guinea pigs, and cats. Vision Research, 1974, 14, 725-729.

Creel. D. J., Dustman, R. E., \& Beck, E. C. Differences in visually evoked responses in albino versus hooded rats. Experimental Neurology, 1970, 29, 298-309.

Fleming. D. E., \& Bigler, E. D. Relationship between photically evoked after-discharge occurrence and hippocampal EEG rhythms in restrained and unrestrained albino rats. Physiology \& Behavior, 1974, 13, 757.761.

Fleming, D. E., Rhodes, L. E., Wilson, C. E., \& Shearer, D. E. Time-drug modulations of photically evoked afterdischarge patterns. Physiology \& Behavior, 1972, 8, 1045-1049.

Fleming, D. E., Rhodes, L. E., Wilson, C. E., \& Shearer, D. E. Differential effects of convulsive drugs on photically evoked after-discharge parameters. Psychopharmacologia, 1973, 29. 77-84.

Fleming, D. E., Shearer, D. E., \& Creel, D. J. Effect of pharmacologically induced arousal on the evoked potential in the unanesthetized rat. Pharmacology. Biochemistry. and Behavior, 1974, 2. 187-192.

Fleming, D. E., Wilson, C. E., \& Shearer, D. E. Strain differences in the elicitation of electro-cortical after-discharge. Physiology \& Behavior, 1973, 10, 879-885.

Gelbrich, D., Klingberg, F., \& Rebentisch, E. Das Auftreten photisch ausgeloster Nachentladungen in Abhangigkeit von der Lichtreizform. Acta Biologica et Medica Germanica, 1972, 29. 923-927.

HERON, W., \& ANCHEL, H. Synchronous sensory bombardment of young rats: Effects on the electroencephalogram. Science, $1964,145,946-947$.

Hilgard, E., \& Bower, G.Theories of learning. New York: Appleton-Century-Crofts, 1966.

John, E. R., Bartlett, F., Shimoxoch, M., \& Kleinman, D. Neural readout from memory. Journal of Neurophysiology, 1973 , 36. 893-924.

KImURA. D. Multiple response of visual cortex of the rat to photic stimulation. Electroencephalography and Clinical Neurophysiology, 1962, 14, 115-122.

KLINGBERG, F. Hypersynchrony and learning. In G. Adam (Ed.), Biology of memory. Budapest: Akademiai Kiado, 1970.

KLINGBERG, $\bar{F}$. Correlated effects of prenatal $x$-ray-irradiation on the ECoG and behaviour of rats. In L. Jilek and S. Trojan (Eds.) Proceedings of the International Symposium Neuroontogeneticum: PRAGA, 1967.

Klingberg. F., \& Pickennain, L. Der Einflub des Verhaltens aud die photisch ausgeloste Rekrutierung. Acta Biologica et Medica Germanica, 1967, 19, 267-283.

Kingberc, F., \& Pickenhain, L. Die photisch ausgeloste Rekrutierung und ihre Beziehung zu den photisch ausgelosten Nachentladungen. Pflugers Archiv, 1966, 292, 161-176.

Klingberg, F., \& Schwartze, P. Uber photisch ausgeloste Nachentladungen im visuellen Cortex der Ratte wahrand der Ontogenese. Pflugers Archiv, 1966, 292, 90-99.

Kohler, M., \& KIINGberg, F. Photisch und elektrisch ausgeloste Nachentladungen im visuellen Kortex der Ratte vor und nach Ausschaltungen im visuellen System. Acta Biologica et Medica Germanica, 1971, 26, 697-710.

KoHler, M., \& KLINgberg, F. Vergleich photisch und elektrisch ausgeloster Nachentladungen im visuellen Kortex de Ratte. Acta Biologica et Medica Germanica, 1969, 23, 85-97.
Pickenhain, L., \& Kinngberg, F. Behavioral and electrophysiolotical changes during avoidance conditioning to light flashes in the rat. Electroencephalography and Clinical Neurophysiology, 1965, 18, 464-476.

Pond, F. J., \& SChwartzbaum, J. S. Interrelationships of hippocampal EEG and visual evoked responses during appetitive behavior in rats. Brain Research, 1972, 43, 199-137.

Rhodes, L. E., \& Fleming, D. E. Sensory restriction in the albino rat: Photically evoked after-discharge correlates. Electroencephalography and Clinical Neurophysiology, 1970, 29. 488-495.

Rosenfeld, J. P., \& Owen, P. L. Instrumental conditioning of photic evoked potentials: Mechanisms and properties of late component modification. Physiology and Behavior, 1972, 9, 851-858.

SChWARTZbaum, J. S. Interrelationship among multiunit activity of the midbrain reticular formation and the lateral geniculate nucleus, thalamocortical arousal, and behavior in rats. Journal of Comparative and Physiological Psychology, 1975, 89. 131-157.

Schwartzbaum, J. S., Kreinick, C. J., \& Mello, W. F. Cortical evoked potentials any synchronization of electrocortical activity during consummatory behavior in rats. Brain Research, 1972 , 36. 171-182.

Schwartzbaum, J. S., Kreinick, C. J., \& Gustafson, J. W. Cortical evoked potentials and behavioral reactivity to photic stimuli in freely moving rats. Brain Research, 1971, 27, 295-307.

Shearer, D. E., Fleming, D. E., Bigler, E. D., \& Wilson, C. E. Suppression of photically evoked afterdischarge bursting following administration of anticonvulsants in waking rats. Pharmacology, Biochemistry, and Behavior, 1974, $2,839-842$.

Sumitomo, I., \& KLINGBERG, F. The role of lateral geniculate body in the generation of photically and electrically evoked afterdischarges is freely moving rats. Acta Biologica et Medica Germanica. 1972. 29. 43-54. (a)

Sumitomo. I..\& KLINGBERG. F. Influence of visual cortex lesions upon photically evoked afterdischarges of the superior colliculus in freely moving rats. Acta Biologica et Medica Germica, 1972, 29, 236-246. (b)

Sumitomo, I., \& KIINGBerg, F. The influence of repetitive stimulation of colliculus superior upon photically evoked responses in freely moving rats. Acta Biologica et Medica Germanica, 1972, 29. 929-932. (c)

TheIL, S., \& KLINGBERG, F. Influence of nucleus centralis medialis of thalamus on the information processing in the lateral geniculate body of freely moving rat. Acta Neurobiologiae Experimentalis (Warszawa), 1971, 31, 373-382.

WINER, B. J. Statistical principles in experimental design. New York: McGraw-Hill, 1962.

YelliN, A. M.. \& Jerison, H. J. Visual evoked potentials and inter-stimulus intervals in the rat. Electroencephalography and Clinical Neurophysiology, 1973, 34, 429-432.

(Received for publication August 18, 1975; August 28, 1975.) 